criticised as being sometimes trivial. We will continue to accept a few case reports and short papers, but they will in future be presented in the same format as major papers and will therefore be available as reprints. Authors should be warned that case reports need to have a definite and worthwhile message to justify acceptance - the merely unusual or coincidental will attract the comment "so what", and join the high proportion of rejections.

These changes have been made to improve our service to both authors and readers; our 'Guide to Authors' has been amended.

PHILIP FULFORD

\title{
Magnetic resonance imaging of meniscal tears of the knee
}

Like many new techniques, MRI of the menisci of the knee had a brief honeymoon period when it seemed to be the answer to many diagnostic problems. Later, the various anatomical pitfalls became apparent. Some inexperienced radiologists provided overconfident reports, and some arthroscopists developed a degree of scepticism, while questioning the costs. The centenary of imaging is an appropriate time to take stock.

There is now good evidence that MRI is an accurate method of assessing meniscal tears (Crues et al 1987; Polly et al 1988; Glashow et al 1989; Fischer et al 1991; Raunest et al 1991; Heron and Calvert 1992; Mink et al 1993). A multicentre review of 2000 patients assessed by both MRI and arthroscopy showed an overall accuracy for the medial meniscus of 0.89 with a sensitivity of 0.93 and a specificity of 0.84 (Mackenzie et al 1996a). An MRI diagnosis of a tear in a medial meniscus was confirmed by arthroscopy in $87 \%$ (predictive value of a positive test $=0.87$ ), and that of normality was correct in $91 \%$ (predictive value of a negative test $=0.91$ ). Overall accuracy for the lateral meniscus was similar, but the sensitivity was much lower (0.76) and the specificity was higher (0.94). In certain specialist centres, this diagnostic performance may even be better (Justice and Quinn 1995).

Accuracy is clearly important, but it is also pertinent to consider how much MRI can help clinicians with diagnostic and management decisions. Referall for an MRI should imply that there is some diagnostic uncertainty. A patient with classical locking after acute injury usually warrants early arthroscopy; the clinical diagnosis can be confirmed and the lesion can be treated at the same proced-

A. K. Dixon, MD, FRCR, FRCP, Professor of Radiology Department of Radiology, University of Cambridge School of Clinical Medicine, Addenbrooke's Hospital, Box 219, Hills Road, Cambridge CB2 2QQ.

(C)1996 British Editorial Society of Bone and Joint Surgery 0301-620X/96/21149\$2.00

J Bone Joint Surg [Br] 1996;78-B:174-5. ure. When the clinician is uncertain of both the diagnosis and the need for arthroscopy, MRI is of considerable help. Several studies have shown that it can refine (and even refute) the initial clinical diagnosis and contribute to the decision on the need for arthroscopy (Boeree et al 1991; Ruwe et al 1992; Spiers et al 1993; Mackenzie et al 1996b). It has been argued that the appropriate use of MRI may reduce the number of diagnostic arthroscopies, allow earlier treatment of knees which require therapeutic arthroscopic procedures, and even reduce overall costs (Warwick et al 1993; Birch et al 1994).

Despite these encouraging arguments, some startling discrepancies are still found between MRI and arthroscopic findings. There are several causes. First, there are genuine MRI errors. False-positive MRI results are sometimes due to over-reporting of the very common increase in signal intensity within the posterior third of the medial meniscus. This is due to central myxoid degeneration, part of normal ageing, and the appearance is accentuated by certain MRI sequences (Peterfy et al 1994). It is often difficult to decide whether or not this degeneration extends to the surface of the meniscus. Some apparent extensions to the surface probably represent previous tears which are stable and require no arthroscopic intervention. It is now well recognised that a meniscus can heal (Newman, Daniels and Burks 1993) and that an abnormal signal may persist after healing. There is thus a case for selective non-operative treatment (Weiss et al 1989); this may reduce some longterm degenerative changes (Fairbank 1948).

Other false-positive MRI reports may arise from anatomical pitfalls such as the attachment of the intermeniscal ligament, but these are now reasonably well understood. An effusion is generally beneficial for the detection of meniscal lesions, since the fluid in any defect is conspicuous on T2weighted images. At some sites, however, fluid may interpose between the meniscus and the capsule; this will depend on the precise anatomy of the meniscocapsular junction, but peripheral tears or meniscocapsular separation may be simulated.

There are numerous causes for false-negative MRI results (Quinn and Brown 1991; De Smet et al 1994; 
Justice and Quinn 1995; Mackenzie et al 1995). A long delay between MRI and arthroscopy may have allowed a new injury. A lesion can be missed because of technical factors (Lomas, Mackenzie and Dixon 1993), but this is now rare. Radiologists are sometimes confused by normal anatomical variation (Mink et al 1993), especially in relation to the lateral meniscus where sensitivity is low (De Smet and Graf 1994; Mackenzie et al 1996a).

True errors of perception, missing a lesion, are also possible, especially when radiologists report from hardcopy images alone. It is best to review the electronic data, since this allows images to be studied at different viewing parameters. The window level and width can significantly change the appearance and make obvious the presence and nature of a lesion (Koehler, Anderson and Baxter 1979; Buckwalter et al 1993). The integrity of a meniscus may be better appreciated after the manipulation of three-dimensional data; this gives more information about the site and shape of a tear (Disler et al 1993).

A knee which has been operated on is always a diagnostic challenge (Dandy and Jackson 1975) and falsepositive MRI results may occur. Surgical trimming of a meniscus may have extended almost to an area of myxoid degeneration, and MRI may erroneously suggest a persisting defect (Mink et al 1993). MRI arthrography has been recommended for postoperative knees (Applegate et al 1993); the presence or absence of dilute gadolinium entering meniscal defects is useful. Most surgical procedures and especially diathermy leave scars (Small, Hacking and Dixon 1995) which interfere with the homogeneity of the magnetic properties of tissues; these create artefacts on MRI which can simulate loose bodies and other lesions. Surgical repair of a meniscus can create further difficulties and confusion of diagnosis.

All the above has assumed that arthroscopy is completely accurate, but diagnostic reports vary with the technical skill and experience of the arthroscopist. It is recognised that the posterior thirds of some menisci, particularly their inferior surfaces, are difficult to visualise (Ireland, Trickey and Stocker 1980; Levinsohn and Baker 1980; Selesnick et al 1985), and it is probably no coincidence that a high proportion of supposedly false-positive MRI errors occur at such sites (Quinn and Brown 1991). Tears are sometimes found at a second-look arthroscopy (Boeree et al 1991) and different arthroscopic portals may be needed to see all parts of the menisci (Tolin and Sapega 1993).

Errors in MRI have been classified as 'true' and 'false', depending on whether the MRI report was proven to be wrong, or there was an alternative explanation such as an arthroscopic misdiagnosis. Such judgements require close collaboration between radiologists and arthroscopists, which has its own merits. If controversial errors are reclassified in this way, the diagnostic performance of MRI improves considerably, reaching a specificity of 0.99 (Mackenzie et al 1995).

Such statistics mean little to individual patients. They are best served when they are seen by an experienced clinician, who makes selected referrals for MRI to a specialist radiologist. The latter should have access to good equipment and should review the images on a work-station. Ideally, the radiologist and the clinician should then discuss their findings and try to resolve any disagreements. In this way their combined skills will improve - to the benefit of future patients.

ADRIAN K. DIXON

\section{REFERENCES}

Applegate GR, Flannigan BD, Tolin BS, Fox JM, Del Pizzo W. MR diagnosis of recurrent tears in the knee: value of intraarticular contrast material. Am J Roentgenol 1993;161:821-5.

Birch N, Powles D, Dorrell H, et al. The investigation and treatment of disorders of the knee: indications and a cost-comparison of arthroscopy and magnetic resonance imaging. Health Trends 1994;26:50-2

Boeree NR, Watkinson AF, Ackroyd CE, Johnson C. Magnetic resonance imaging of meniscal and cruciate injuries of the knee. $J$ Bone Joint Surg [Br] 1991;73-B:452-7.

Buckwalter KA, Braunstein EM, Janizek DB, Vahey TN. MR imaging of meniscal tears: narrow versus conventional window width photographs. Radiology 1993;187:827-30.

Crues JV, Mink JH, Levy TL, et al. Meniscal tears of the knee: accuracy of MR imaging. Radiology 1987;164:445-8.

Dandy DJ, Jackson RW. The diagnosis of problems after meniscectomy. J Bone Joint Surg [Br] 1975;57-B:349-52.

De Smet AA, Graf B. Meniscal tears missed on MR imaging: relationship to meniscal tear patterns and anterior cruciate tears. Am J Roentgenol 1994;162: 905-11.

De Smet AA, Tuite MJ, Norris MA, Swan JS. MR diagnosis of meniscal tears: analysis of causes of errors. Am J Roentgenol 1994;163: 1419-23.

Disler DG, Kattapuram SV, Chew FS, Rosenthal DI, Patel D. Meniscal tears of the knee: preliminary comparison of three dimensional MR reconstruction with two dimensional MR imaging and arthroscopy. Am J Roentgenol 1993;160:343-5.

Fairbank J. Knee joint changes after meniscectomy. J Bone Joint Surg [Br] 1948;30-B:664-70.

Fischer SP, Fox JM, Del Pizzo W, et al. Accuracy of diagnosis from magnetic resonance imaging of the knee: a multicentre analysis of one thousand and fourteen patients. J Bone Joint Surg [Am] 1991;73-A:2-10.

Glashow JL, Katz R, Schneider M, Scott WN. Double blind assessment of the value of magnetic resonance imaging in the diagnosis of anterior cruciate and meniscal lesions. J Bone Joint Surg [Am] 1989;71-A: 113-9.

Heron CW, Calvert PT. Three-dimensional gradient echo MR imaging of the knee: comparison with arthroscopy in 100 patients. Radiology 1992; 183:839-44.

Ireland J, Trickey EL, Stocker DJ. Arthroscopy and arthrography of the knee: a critical review. J Bone Joint Surg [Br] 1980;62-B:3-6.

Justice WW, Quinn SF. Error patterns in the MR imaging evaluation of menisci of the knee. Radiology 1995;196:617-21.

Koehler PR, Anderson RE, Baxter B. The effect of computed tomography viewer controls on anatomical measurements. Radiology 1979; 130:189-94.

Levinsohn EM, Baker BE. Prearthrotomy diagnostic evaluation of the knee: review of 100 cases diagnosed by arthrography and arthroscopy. Am J Roentgenol 1980;134:107-11.

Lomas DJ, Mackenzie R, Dixon AK. Magnetic resonance imaging of the knee: does foot restraint improve the examination? $\mathrm{Br} J$ Radiol 1993;66:497-502.

Mackenzie R, Palmer CR, Lomas DJ, Dixon AK. Magnetic resonance imaging of the knee: diagnostic performance statistics. Clin Radiol 1996a;51:in press.

Mackenzie R, Dixon AK, Keene GS, et al. Magnetic resonance imaging of the knee: assessment of effectiveness. Clin Radiol 1996b;51:in press.

Mackenzie R, Keene GS, Lomas DJ, et al. Errors at knee MRI: true or false? Br J Radiol 1995;68:1045-51. 
Mink JA, Reicher MA, Crues JV, Deutch AL. MRI of the knee. Fourth ed. New York: Raven Press, 1993.

Newman AP, Daniels AU, Burks RT. Principles and decision making in meniscal surgery. Arthroscopy 1993;9:33-51.

Peterfy C, Janzen D, Tirman P, et al. 'Magic angle' phenomenon: a cause of increased signal in the normal lateral meniscus on short-TE MR images of the knee. Am J Roentgenol 1994;163:149-54.

Polly DW, Callaghan JJ, Sikes RA, et al. The accuracy of selective magnetic resonance imaging compared with the findings of arthroscopy of the knee. J Bone Joint Surg [Br] 1988;70-B:192-8.

Quinn SF, Brown TF. Meniscal tears diagnosed with MR imaging versus arthroscopy: how reliable a standard is arthroscopy? Radiology 1991; 181:843-7.

Raunest J, Oberle K, Loehnert J, Hoetzinger $\mathbf{H}$. The clinical value of magnetic resonance imaging in the evaluation of meniscal disorders. J Bone Joint Surg [Am] 1991;73-A:11-6.

Ruwe PA, Wright J, Randall RL, et al. Can MR imaging effectively replace diagnostic arthroscopy? Radiology 1992;183:335-9.
Selesnick FH, Noble HB, Bachman DC, Steinberg FL. Internal derangement of the knee: diagnosis by arthrography, arthroscopy and arthrotomy. Clin Orthop 1985;196:26-30.

Small JH, Hacking JC, Dixon AK. Detection of portals for knee arthroscopy by magnetic resonance imaging. Roentgen Centenary Congress Book of Abstracts 1995:420.

Spiers ASD, Meagher T, Ostlere SJ, Wilson DJ, Dodd CAF. Can MRI of the knee affect arthroscopic practice? a prospective study of 58 patients. J Bone Joint Surg [Br] 1993;75-B:49-52.

Tolin B, Sapega A. Arthroscopic visual field mapping at the medial meniscus: a comparison of different portal approaches. Arthroscopy 1993;9:265-71.

Warwick DJ, Cavanagh P, Bell M, Marsh CH. Influence of magnetic resonance imaging on a knee arthroscopy waiting list. Injury 1993; 24:380-2.

Weiss CB, Lundberg M, Hamberg P, DeHaven KE, Gillquist J. Nonoperative treatment of meniscal tears. J Bone Joint Surg [Am] 1989; 71-A:811-22.

\section{Prospects for the treatment of spinal cord and peripheral nerve injury}

After severe musculoskeletal trauma it is usually possible to reconstruct the skeletal elements of the injury, but any significant neurological damage may limit the functional outcome. For this reason injuries to the nervous system require careful management to maximise recovery. Despite new knowledge of such injuries and the potential for regeneration, there is need for further research.

Peripheral nerves are known to be able to regenerate; divided axons can grow distally and reconnect with target organs. This may occur spontaneously when the nerve is in continuity and there is no severe damage to its connectivetissue elements, but after division or severe damage, surgical repair is indicated. Research on the biology of peripheral nerve regeneration has led to the identification of neurotrophic factors which influence the process (Lundborg et al 1982; Lundborg 1988; Loughlin and Fallon 1992). It has not yet been possible to make use of these growth factors. Determining which factors are clinically important is very difficult and the method, timing, extent, site, and duration of delivery remain to be established. Experimental work suggests a potential role for these factors in nerve

T. E. J. Hems, MA, DM, FRCS, FRCS Ed(Orth), Senior Registrar in Trauma and Orthopaedic Surgery

The Nuffield Orthopaedic Centre NHS Trust, Windmill Road, Headington, Oxford OX3 7LD, UK.

M. A. Glasby, MA, MSc, FICS, FRCS, FRCS Ed, Reader in Anatomy Department of Anatomy, University of Edinburgh Medical School, Teviot Place, Edinburgh EH8 9AG, UK.

Correspondence should be sent to Mr M. A. Glasby.

(C)1996 British Editorial Society of Bone and Joint Surgery 0301-620X/96/21183 \$2.00

J Bone Joint Surg [Br] 1996;78-B:176-7. repair but has not yet derived enough firm data for clinical use.

Successful axonal regeneration requires the presence of these neurotrophic factors, largely produced by proliferating Schwann cells in the distal stump, and of a basementmembrane matrix containing certain macromolecules to which axons can attach. The beneficial effect of the distal segment of nerve helps to explain the widely accepted observation that early repair of a nerve increases the chance of satisfactory outcome (Birch 1992). To provide a suitable basement membrane across a gap in peripheral nerve freeze-thawed muscle grafts have been developed as an alternative to nerve grafts (Glasby et al 1986, 1990). These give a similar basement-membrane matrix, but their effectiveness is limited by the lack of Schwann cells and hence of any neurotrophic factors.

In contrast to the peripheral nervous system, axons in the central nervous system (CNS) do not show any functionally significant regeneration. There has been considerable research on the pathophysiology of CNS damage, particularly in the spinal cord. It is now known that axons in the CNS do have the ability to regenerate, but are inhibited by the microenvironment provided by non-neuronal cells (Fehlings and Tator 1988). Two new approaches to spinal-cord repair have been reported. Schnell et al (1994) have used a combination of the growth factor, neurotrophin-3, and antibodies against inhibitory proteins; they showed enhanced regeneration of corticospinal axons in the spinal cord of the adult rat. Iwashita, Kawaguchi and Murata (1994) found some functional recovery after using fetal spinal cord to repair the spinal cord of neonatal rats. These results are encouraging but any clinical application is clearly a long way off. 